\title{
NOTAS
}

\section{DE LA COLONIZACIÓN ALFABÉTICA CONSIDERADA COMO UNA DE LAS ARTES DEL SUJETO}

Desde inicios de la Conquista ha habido colonización en América y el proceso colonizador ha abarcado, de una forma u otra, todos los campos de la sociedad y de la cultura, incluyendo también el lenguaje y, además, la escritura. Solemos pensar muchas veces que este proceso de colonización se funda en una distinción inequívoca entre colonizador y colonizado, entre sujeto y objeto, entre lo propio y lo ajeno y que supone la reducción de lo uno a lo otro. En este caso los españoles serían simplemente los colonizadores o conquistadores del mundo de los indios recién descubiertos, y los indígenas serían a su vez los colonizados o los vasallos de los espanoles. Consiguientemente podríamos imaginar que los europeos no hicieron más que importar al Nuevo Mundo su propia escritura en letras, para inculcarla a las poblaciones que carecían de alfabeto. De esta suerte los conquistadores habrían ocupado un espacio sonoro todavía vacío con su propio abecedario latino y la voz ajena de los vencidos se habría rendido simplemente a los signos escritos de los invasores. Sin embargo, tenemos que preguntarnos si tal dicotomía casi maniquea entre un agresivo alfabeto colonizador y una indefensa voz colonizada puede aún aceptarse desde que conocemos aquella famosa dialéctica hegeliana que reina entre las conciencias del amo y del criado ${ }^{1}$. No sería casualidad el hecho de que, en su cabal Pedagogía del oprimido, Paulo Freire enfocara la idiosincrasia americana de la realidad opresora a partir de la dialéctica del amo y el criado para enlazarla precisamente con la cuestión de la alfabetización ${ }^{2}$.

Pero aquí no vamos a pisar ni las venerables huellas de la dialéctica ni la pedagogía de la alfabetización. En lugar de esto qui-

${ }^{1}$ Cf. Georg Wilhelm Friedrich Hegel, Phänomenologie des Geistes, cap. 4 A.

${ }^{2}$ Paz e Terra, Rio de Janeiro, pp. 27-61. 
siéramos proponer un enfoque posmoderno, partiendo de las contradicciones y complejidades que lleva en sí la categoría de una subjetividad colonizadora y colonizada a la vez. Pues como Michel Foucault ha señalado en sus escritos tardíos sobre la historia de la sexualidad, existe una serie de actitudes o técnicas en las que ya no cabe la separación simplista entre sujeto y objeto porque ambas instancias se confunden. Se trata de una clase de comportamientos que Foucault llama "techniques de soi" o también "arts de soi"3. Estas son aquellas disposiciones del sujeto cuyo objeto resulta ser el sujeto mismo, en cuanto provoca efectos dentro de sí. A Foucault le interesan sobre todo actitudes tales como la introspección, el autoanálisis o el examen de conciencia, y subraya a menudo que estas conductas no están basadas solamente en una exclusión negativa, más bien constituyen un rasgo positivo particular porque cercan como un terreno interno y posibilitan un arte del sujeto que éste sabrá imponer a sí mismo. Esto equivale a decir que las artes del sujeto engendran una "estética de la existencia" ${ }^{4}$ que se sitúa más allá del sujeto y el objeto, más allá de lo propio y lo ajeno, más allá del colonizador y el colonizado, valga "más allá" en el sentido que le ha dado Federico Nietzsche en sus estudios genealógicos ${ }^{5}$.

Pero la técnica del sujeto que nos preocupa aquí, no será la problemática del sexo tal como Foucault la precisó, sino la relación que puede establecerse entre escritura y voz, entre sonido y letra. Los trabajos de Walter Ong han puesto claramente de relieve que la conexión respectiva entre la lengua hablada y los caracteres escritos de un sistema gráfico será de máxima trascendencia para cualquier sujeto hablante una vez que éste sepa escribir 6 . Se creará inevitablemente un arte del sujeto arraigado en la relación entre voz y escritura. Hemos escogido, para nuestro propósito, un caso significativo. A finales del siglo xv e inicios del XvI, se forma en Europa un nuevo discurso gramatical sobre las lenguas vernáculas. Algunas décadas más tarde, éste se traslada a lo que entonces era la Nueva España. Si nuestros ejemplos resultan representativos, servirán a lo mejor, como veremos más adelante, para desmantelar algunos inveterados tópicos que sostienen nuestro concepto de colonización.

${ }^{3}$ Cf. L'usage des plaisirs: le Souci de soi, Histoire de la sexualité, Gallimard, Paris, 1984 , t. 2, pp. $1-19$.

${ }^{4}$ Ibid., t. 2, p. 18.

${ }^{5}$ Cf. Jenseits von Gut und Büse: Zur Genealogie der Moral.

${ }^{6}$ Cf. Orality and literacy. The technologizing of the word, Methuen, London-New York, 1982, pp. 78-116. 
En sus comienzos, el alfabeto escrito no ejerce necesariamente sobre la voz humana la tiranía que se le ha reprochado a veces ${ }^{7}$. Por la falta de signos vocálicos, los primeros alfabetos semíticos preservan en efecto los sonidos contra la absorción irremediable por la escritura. Y aunque las dos escrituras clásicas europeas están provistas de letras vocálicas, en ellas todavía subsiste, según atestiguan los antiguos gramáticos, una diferencia bien clara entre la voz sonora y los caracteres alfabéticos. Pero la situación cambia radicalmente en el Renacimiento cuando se está formando un conjunto de nuevas artes del sujeto que preludian la Edad Moderna. De paso, en la Península ibérica emerge un nuevo discurso gramatical sobre el idioma vernáculo que se difundirá no sólo por Europa, sino también por las Indias Orientales y Occidentales. El primer y más ilustre representante de esta nueva escuela de gramáticos vulgares será el humanista andaluz Antonio de Nebrija, quien en 1492 publica en Salamanca su Gramática de la lengua castellana, y en 1517, en Alcalá de Henares, las Reglas de ortographía ${ }^{8}$. Encuentra buen número de seguidores en los países de lenguas romances. En cuanto a su doctrina ortográfica, Juan Jorge Trissino en Italia (1524), Jacobo Dubois (1531) y Luis Meigret (1542) en Francia así como Fernando de Oliveira en Portugal (1536) expresarán tendencias muy parecidas.

Este discurso implantará una nueva concepción de la lengua vulgar en las mentes de los sujetos hablantes. El "ars grammatica", que hasta entonces sólo había regulado los idiomas clásicos, ahora codificará igualmente las hablas vernáculas de todos los días 9 , convirtiéndose por consiguiente en un riguroso arte de sí. La transformación epistemológica también toca al concepto de la escritura. En la Antigüedad y aun en la Edad Media, los signos escritos se habían considerado como productos culturales que correspondían a un idioma determinado. En este sentido las lenguas vernáculas sólo podían usurpar la escritura o emplearla en forma impropia

7 La expresión de la "tiranía del alfabeto" fue acuñada por Roy Harris, The origin of writing, Open Court, La Salle, 1986, pp. 29-56. Al mismo hecho alude Walter D. Mignolo, "Literacy and colonization: The New World experience", en 1492-1992: Re/Discovering Colonial writing, eds. R. Jara \& N. Spadaccini, The Prisma Institute, New York, 1989, pp. 51-96, y 53-58.

${ }^{8}$ Me refiero a la Gramática de la lengua española, editada por A. Quilis (Edit. Nacional, Madrid, 1980) y a las Reglas de orthographía en la lengua castellana, publicadas en esta misma Gramática de la lengua castellana, ahora en la edición de I. González Llubera (Oxford University Press, Oxford, 1926, pp. 229-260).

${ }^{9}$ Cf. Ivan Illich, "Das Recht auf die gemeine Sprache”, Vom Recht auf Gemeinheit, Reinbek bei Hamburg, Rowohlt, 1982, pp. 11-29. 
porque constituían un medio de expresión esencialmente oral. El uso de la escritura, por el contrario, o más exactamente del alfabeto sólo caracterizaba a una civilización local ${ }^{10}$. Pero con Nebrija las letras pasan a ser los requisitos universales e imprescindibles de cualquier civilización humana. Frente al alfabeto, la escritura jeroglífica, sobre todo la de los egipcios, le parece imperfecta y provisional. En el transcurso del tiempo, supone Nebrija, todas las naciones han aprendido a manejar la escritura literal de manera que el alfabeto está a la disposición de todos cuantos quieran grabar los sonidos de la voz humana ${ }^{11}$.

La definición nebrisense de la letra se opone implícitamente a las teorías de Prisciano, gramático romano del siglo vi. Para éste la letra se caracterizaba por su nombre, por su fuerza para expresar determinados sonidos y por su figura ${ }^{12}$. Nebrija empieza, empero, su explicación por la negación: "De manera que no es otra cosa la letra, sino figura por la cual se representa la voz"13. Como consecuencia "la diuersidad delas letras no está en las figuras dellas, sino enla diuersidad dela pronunciación" (Ortographía, p. 238). A Nebrija sólo le importa que la letra represente un sonido. La figura, es decir, la "Gestalt" de la letra es un mero accidente. La materialidad del signo escrito se esfuma y las letras pierden su sustancia figural, se ven desfiguradas y desustancializadas. Mientras que en sus célebres Introductiones latinae, que le valieron su fama de grámatico, Nebrija sigue de cerca la doctrina de Prisciano, en sus tratados sobre el romance se aleja justamente de la autoridad antigua ${ }^{14}$. Para Prisciano, una multitud de sonidos se confrontaba con un inventario muy limitado de letras ${ }^{15}$. Pero Nebrija supone un conjunto de sonidos a los que han de corresponder otras tantas letras; cada letra remitirá a un solo sonido y viceversa (Ortographía, p. 238). Para el castellano, Nebrija comprueba veintiséis sonidos con sus correlatos gráficos ${ }^{16}$ e inventa la

${ }^{10}$ Esta concepción es explicada de modo ejemplar por Dante Alighieri en su tratado De vulgari eloquentia.

11 Cf. Gramática castellana, t. 1, cap. 2, p. 107; Orthographía, p. 234.

12 Cf. Prisciani institutionum grammaticarum libri XVIII, M. Hertz, en Grammatici latini, ed. H. Keil, B. G. Teubner, Lipsiae, 1855, t. 1, pp. 5-7.

13 Gramática castellana, t. 1, cap. 3, p. 111.

14 Cf. Antonii Nebrissensis introductiones latinae (Samanticae, 1481), ed. facs. E. Burgos, Visedo, 1981. Para la influencia de Prisciano sobre Nebrija véase el "Estudio" de Quilis, en su ed. de la Gramática castellana de Nebrija.

15 Prisciani institutionum grammaticarum libri XVIII, t. 1, p. 5.

16 Cf. Gramática castellana, t. 1, cap. 5, p. 116. 
representación literal biunívoca. Quizá por primera vez los mudos caracteres del alfabeto, que siempre habían sido reputados de inferiores, pregonan su igualdad de derechos y aun su superioridad frente a la voz sonora.

La identidad de cada clase de sonidos se ve sancionada por la atribución a la letra respectiva. Por supuesto, esta construcción de identidades sonoras no imita la realidad vocal, sino el orden de las letras inmutables. Las diferencias y equivalencias entre los sonidos se basan ocultamente en los signos escritos mismos. Este mecanismo salta a los ojos cuando Nebrija justifica la separación de B y V, que para él son dos entidades distintas: si muchos las confunden, lo hacen por error, "siendo entre ellas tanta differencia, quanta puede ser entre qualesquier dos letras” (Ortographía, p. 247). En tales casos será inevitable restituir una pronunciación correcta que corresponda a la escritura; se exige, evidentemente, lo que convendría llamar un arte del habla ortográfica. De la doctrina nebrisense emanará casi espontáneamente la técnica de una pronunciación sometida a los moldes de la escritura. El habla ortográfica será así, una de las artes que el sujeto deberá aprender a inicios de la Edad Moderna.

Para la situación española sólo habrá que recordar el Diálogo de la lengua, compuesto hacia 1535 en Nápoles por Juan de Valdés ${ }^{17}$. Este tratado nos muestra cómo la disciplina del cortesano, analizada por Norbert Elias, invade también al individuo hablante ${ }^{18}$. Valdés no se cansa de aconsejar "cuidado", "miramiento", "observancia" y "trabajo" a los que quieran escribir y pronunciar correctamente el castellano. Los sonidos se asimilarán a las letras. Así se soterra la diferencia inmemorial entre voz y escritura para que en su lugar se establezca una identidad fantasmal de la una con la otra. Si la diferencia desaparece, esto no conduce sin embargo al "fonocentrismo", como imagina Jacques Derrida19, sino a un "gramatocentrismo", es decir, a la subordinación deliberada de la voz bajo la escritura. De ahí resalta toda ambigüedad del conocido

17 Utilizo la edición de C. Barbolani, Cátedra, Madrid, 1982.

18 Der Prozess der Zivilisation (1938), 2a ed., Francke, Bern, 1969, ts. 1-2. Cf. también Lore Terracine, Lingua come problema nella letteratura spagnola del Cinquecento, Stampatori, Torino, 1979, pp. 3-86. Para más detalles sobre el discurso gramatical renacentista véase también nuestro estudio Körper, Traum, M. Niemeyer, Tübingen, 1989, pp. 20-51.

${ }^{19}$ Para la noción de "diferencia" véase JacQues Derrida, "La diffé", en FouCAult et al., Théorie d'ensamble, Éds. du Seuil, Paris, pp. 41-66; para el "fonocentrismo", véase Derrida, De la grammatologie, Minuit, Paris, 1967, pp. 15-108. 
axioma nebrisense: "Que así tenemos de escrivir como pronunciamos, \& pronunciar como escrivimos" 20.

Resumiendo podríamos decir que en el discurso nebrisense el sonido es considerado, para emplear los términos escolásticos, como materia mientras que la letra funciona como forma. Esta repartición ordena que la voz dependa de la escritura, "quia materia est propter formam, et non e converso"21. Al mismo tiempo reconocemos en la oposición entre sonido material y letra formal un esquema que según Tzvetan Todorov rige el universo mental de muchos conquistadores, pues nota que la relación de materia y forma es homóloga a la de indio y español, a la de colonizado y colonizador 22 . Por ende, la estructura de colonización e incluso de repartimiento ya es inherente al proyecto de alfabetización de las lenguas vulgares. Así el discurso gramatical renacentista enseña a los europeos a colonizar su propia voz.

A diferencia de lo expuesto, las antiguas civilizaciones amerindias están basadas en una experiencia muy profunda de la distinción entre voz y escritura. Escribir consiste en una actividad aislada, y no es el corolario omnipresente del hablar. Entre los pueblos mesoamericanos hay una casta de expertos que dibujan códices pictográficos; estas imágenes contienen series de conceptos y no de palabras. El "tlamatini" de los aztecas, por ejemplo, es decir, el sabio intérprete de dibujos, tiene que averiguar la pintura que le suministra el "tlacuilo", el diseñador. Sólo posteriormente expresará lo visto con palabras para exponerlo a su público. La significación de los pictogramas no está todavía cuajada en lenguaje ni representa sonidos 23 . De esta manera, las actuaciones vocales resultan irreemplazables. Como la escritura está limitada a un recinto muy reducido y carece por lo tanto de ubicuidad, se destaca por su rareza, pero de forma complementaria se le otorga a la voz algo así como un reservado en el que se desarrolle libremente.

El discurso moderno europeo, por el contrario, oculta precisamente la diferencia entre voz y escritura y recurre al alfabeto como instrumento de mediación universal que sustituye a la voz. Sólo bajo esta consideración entenderemos mejor el choque de

20 Cf. Gramática castellana, t. 1, cap. 5, p. 116.

21 Tomás De AQuino, Summa theologiae, I q. 47, art. 1. p. 159.

22 Cf. La Conquête de l'Amérique: la question de l'autre, Éds. du Seuil, Paris, 1982,

${ }^{23}$ Cf. Birgit Scharlau, \& Mark Münzel, Qellqay-Mündliche Kultur und Schrifttradition bei Indianern Lateinamerikas, Campus, Frankfurt/M.-New York, 1986, pp. $65-80$. 
culturas que provocó el encuentro del Viejo y Nuevo Mundo a inicios de la Conquista. Dentro de muy poco tiempo los idiomas amerindios, y ante todos el náhuatl o mexicano de los aztecas, se escribieron e imprimieron en letras alfabéticas, y esto no sólo por parte de los misioneros europeos sino también de los indígenas. Mucho habrán contribuido los colegios recién fundados, cuyo representante más famoso fue el de Santa Cruz de Tlatelolco, establecido en 1536. Allí, los hijos de la nobleza azteca aprendieron gramática latina y española y se acostumbraron a emplear el alfabeto latino para escribir en su náhuatl materno 24 . El éxito de la escritura alfabética nos demuestra con qué rapidez el discurso de los gramáticos humanistas se trasladó al Nuevo Mundo. Cierto es que se impuso allí con más facilidad que en la Vieja Europa misma donde, en esas décadas, no pocos letrados todavía se disputaban en otras tantas "questioni della lingua" si era lícito escribir en lengua vulgar o no. Obviamente los frailes eruditos que propagaron la alfabetización de los idiomas vernáculos mexicanos no tenían tales escrúpulos.

La alfabetización forzada de las voces indígenas se valió mucho del concepto de una escritura desustancializada y desfigurada. Cuando fray Diego de Landa transcribe en su Relación de las cosas de Yucatán el abecé de los mayas, lo interpreta erróneamente, como si estos veintisiete jeroglíficos fueran meros significantes gráficos sin un peso semántico propio; no se percató de que aquellos significantes estaban asociados indisolublemente con significados determinados ${ }^{25}$. En su abecedario latino ilustrado fray Diego de Valadés se apoya en convicciones muy semejantes y no menos dudosas ${ }^{26}$. Para él, los jeroglíficos indígenas tampoco comportan ningún valor semántico: los dibujos amerindios pueden servirle muy bien para embellecer los caracteres alfabéticos y conciliarse la voluntad de los indígenas. Pero aun así, el fraile tiene que tratar los jeroglíficos como elementos únicamente decorativos y que

24 Véanse Ramón Menéndez Pidal, "Los incunables americanos", en Doctrina cristiana en lengua española y mexicana, Cultura Hispánica, Madrid, 1944, pp. viixxii; y Alfonso Reyes, Letras de la Nueva España, F.C.E., México-Buenos Aires, 1948, pp. 29-42.

25 Cf. Fray Diego de Landa, Relación de las cosas de Yucatán (ca. 1566), ed. M. Rivera, Historia 16, Madrid, 1985, cap. 6, p. 149.

${ }^{26}$ El alfabeto de fray Diego de Valadés se publicó en su Rhetorica christia$n a$ (Perusa, 1559). Una reproducción se encuentra en B. Scharlau, \& M. MüNzEL, op. cit., p. 104. Véase igualmente Mignolo, "Literacy and colonization", pp. 53-56. 
no modifican en nada la significación de las letras. En ambos casos, al alfabeto no se le reconoce una sustancia propia figural e incluso semántica, sino sólo una función representativa. Esta abstracta concepción europea de lo escrito contradice la visión pictórica y por lo tanto sustancialista de los indígenas. Quizás también por este motivo los alumnos alfabetizados más asiduos salían de los nuevos colegios religiosos, allí se les prohibía el contacto con sus familias y con su ambiente tradicional. Los jóvenes aztecas fueron prácticamente trasladados a lo que se podría llamar la "burbuja cultural" de los invasores. Así se complementaban disciplina colegial y proyecto de alfabetización. Claro está que en esta situación los jóvenes mesoamericanos incorporarían las técnicas del sujeto europeo, y entre ellas también figuraría el arte del habla ortográfica. Sin duda, el manejo del alfabeto abriría muchas posibilidades a quienes lo practicaran. Al comparar las limitaciones de los pictogramas chinos y mexicanos con el universalismo de la escritura alfabética, el padre jesuita José de Acosta declara entusiasmado a finales del siglo:

Y al cabo de toda su ciencia [sc. de los chinos], sabe más un indio del Perú o de Méjico, que ha aprendido a leer y escribir, que el más sabio mandarín de ellos, pues el indio con veinticuatro letras que sabe escribir y juntar, escribirá y leerá todos cuantos vocablos hay en el mundo, y el mandarín con sus cien mil letras, estará muy dudoso para escribir cualquier nombre propio de Martín o Alonso27.

Los europeos estaban persuadidos de que con su alfabeto aportaban a los indios una invención muy provechosa e incluso ineludible. Pero el aprendizaje del alfabeto universal fue acompañado en México por el olvido obligado de otras tecnologías gráficas, muy distintas sí, pero no por ello menos valiosas. Las escrituras amerindias tradicionales no fueron abandonadas por rudimentarias o incompletas, sino por demasiado sofisticadas y obviamente también por la violencia perpetrada por los invasores. Para interpretar y transmitir el sistema pictográfico acostumbrado se necesitaban un rico saber y una larga formación, elementos que poco a poco se iban extinguiendo. Por lo tanto, a mediados del siglo, los discípulos trilingües de fray Bernardino de Sahagún estaban capacitados para fijar en letras alfabéticas las explicaciones

27 Historia natural y moral de las Indias (Sevilla, 1590), en Obras del P. José de Acosta, ed. F. Mateos, BAE, Madrid, 1954, lib. 6, cap. 6, p. 187. 
nahuas de los ancianos de Tepepulco sobre sus antiguallas, pero parece improbable que todavía comprendieran la significación de las pinturas que éstos habían trazado 28 .

Sin embargo, en México se mantienen hasta el siglo xvI múltiples formas de lo que se ha llamado "escrituras salvajes"29. Se trata de técnicas que se formaron gracias al contacto de las culturas europea y amerindia. Los ejemplos más famosos son los varios documentos "testerianos" que conocemos. Estos sistemas gráficos ocasionales combinan a su modo pictogramas con jeroglíficos y explotan en ellos semejanzas fonéticas. Estas escrituras salvajes no reprimen totalmente la diferencia entre lo hablado y lo escrito, y además quedan libres del rigor ortográfico del alfabeto. Es probable que el arte del habla ortográfica haya encarado la resistencia de los sectores indígenas menos aculturados de la sociedad colonial.

El primer gramático de lengua amerindia fue Alonso de Molina. Aún niño llegó a la Nueva España bajo Hernán Cortés y aprendió el náhuatl de sus coetáneos. Desde 1524 sirvió de intérprete a los primeros frailes franciscanos, y más tarde ingresó en su orden. Fray Alonso publica en náhuatl varias obras de índole religiosa. De gran interés lingüístico e histórico será su Vocabulario en lengua castellana y mexicana, impreso en México en 1555. En 1571 sale póstumamente una segunda edición, aumentada por un registro mexicano castellano. En el mismo año se edita su Arte de la lengua mexicana y castellana ${ }^{30}$. Al comienzo de este tratado en dos partes, fray Alonso se refiere expresamente a la gramática latina de Nebrija.

Aparentemente, la labor lingüística de fray Alonso se sitúa dentro de la región que cercan las artes europeas del sujeto. El idioma extranjero se codifica por la gramática y el diccionario no sólo para poder predicar como es debido la fe cristiana, sino también para divulgar con mayor éxito entre los indios sus nuevas técnicas. Fray Alonso alude al interrogatorio ante el oidor o médico, y menciona sobre todo el examen de novios y la confesión ${ }^{31}$. Para dominar tan arduas manifestaciones subjetivas hay que reparar con máxima atención en el lenguaje de los indígenas:

28 Cf. Fray Bernardino de Sahagún, Historia general de las cosas de Nueva España, ed. A. M. Garibay K., Porrúa, México, 1975, lib. 2, prólogo, pp. 73-75.

29 Término empleado por B. Scharlau, \& M. MüNzel, op. cit., pp. 99-118.

${ }^{30}$ Fray Alonso de Molina, Vocabulario en lengua castellana y mexicana. Vocabulario en lengua mexicana y castellana (Pedro Ocharte, México, 1571), ed. facs. en Colección de incunables americanos, ts. 4 y 6, Cultura Hispánica, Madrid, 1944, 1945.

${ }^{31}$ Para la confesión como técnica del hombre occidental véase Foucault, $L a$ Volonté de savoir, Histoire de la sexualité, Gallimard, Paris, 1976, t. 1, pp. 76-84. 
Por esta causa debrían los ministros dela Fee y del Euangelio, trabajar con gran solicitud y diligencia, de saber muy bien la lengua de los Yndios... Y para declararles los mysterios de nuestra Fee, no basta saber la lengua como quiera, sino entender bien la propriedad delos vocablos y maneras de hablar que tienen... También tenemos muy entendido y bien experimentado, que para la emienda [sic] y reformación de sus vidas, les aprouecha mucho a estos naturales (como a todos los demás) el sacramento dela penitencia. Pues claro está, que los podrán mal induzir y atraer a la contrición de sus peccados y al examen de su consciencia..., no entendiendo bien lo que dizen. Mal podrá el juez dar sentencia enla causa que no entiende, ni el médico curar la llaga o enfermedad secreta sino sabe lo que dize el enfermo, quando le hace relación de lo que padeze ${ }^{32}$.

¿Qué grámatico europeo hubiera declarado tan abiertamente querer penetrar en la intimidad de los individuos por medio del lenguaje? Mas en el Nuevo Mundo la observación escrupulosa del idioma vernáculo se mezcla naturalmente con el control ajeno y propio del sujeto hablante. No en balde fray Alonso compuso también dos confesionarios nahuas. Más tarde el padre Acosta relatará a qué extremos podía llegar a veces la introducción de la confesión cristiana y la introspección concienzuda en el mundo de los indios:

En el Perú... también se confesaban vocalmente cuasi en todas las provincias... No se acusaban de pecados y actos interiores, y según relación de algunos sacerdotes, después que los cristianos vinieron a la tierra, se acusaban a sus Ichúris o confesores, aun de los pensamientos $^{33}$.

Pero es de notar que la aparición de tales artes del sujeto entre los indígenas se vincula regularmente con los estudios lingüísticos de sus confesores, ya que "se muestra abiertamente cuánto necesita la pericia de la lengua índica” el que habrá de ser su "médico espiritual" 34 .

Mas, ¿qué tiene que ver la implantación de nuevas artes del sujeto con la alfabetización de las lenguas amerindias? Como fray Alonso estima mucho el idioma nahua, le reconoce igual prestigio

32 Molina, "Prólogo al lector", en Vocabulario.

33 Acosta, Historia moral y natural, lib. 5, cap. 25, p. 169.

${ }^{34}$ De procuranda Indorum salute (Salamanca, 1588), en Obras del P. Acosta, cap. 13 , p. 597. 
que a las otras lenguas vulgares, pues la mexicana "no es menos curiosa y delicada que qualquiera delas otras" 35 . Pero para que se despliegue su beldad natural necesita cultivo de parte de los grámaticos, pues igualmente que en los idiomas europeos modernos también en náhuatl hay "dos maneras de pronunciación, la una perfecta y verdadera, y la otra imperfecta y mal pronunciada" 36 . La pronunciación correcta coincide con la lengua empleada "en las cortes delos reyes y príncipes y entre personas yllustres" mientras que la pronunciación defectuosa es característica de "gente labradora y de baxa suerte" $(i d$.). Como la lengua cortesana, pronunciada "congrua y perfectamente" ${ }^{37}$, se entiende en todas partes, ella servirá de modelo, "conforme a las reglas verdaderas y perfectas, con que los más sabios delos mexicanos la pronuncian" $(i d$.$) . Sin$ embargo también los informantes cultos de fray Alonso pecan por algunos errores: "y aunque en algunas partes la pronuncien con algunas incongruidades e imperfectamente, lo regule con las ya dichas reglas deste arte" (id.).

Así el habla nahua correcta no podrá deducirse del uso espontáneo de los aztecas, sino únicamente de la propia gramática de fray Alonso, y por ende la pronunciación nahua dependerá de la escritura alfabética. También el sujeto azteca debe someterse a las reglas del habla ortográfica. Para lograr el dominio de la lengua, se le aconseja que se prodigue en esfuerzos, en "curiosidad", "delicadeza" y "policía" 38 . Esta estilización cortesana no sólo ajusta la voz mexicana a la escritura, sino que también enajena imperceptiblemente al indio de su propia lengua. Por supuesto la normalización intenta igualar el náhuatl con el castellano o el toscano. Pero con todo esto el discurso gramatical se propone simultáneamente colonizar la voz ajena de los indios, imponiéndoles el yugo del habla ortográfica.

La impresionante tentativa de reproducir el discurso europeo en la Nueva España termina, empero, por topar con obstáculos. En un principio también fray Alonso parece aceptar la regla nebrisense de que las letras han de representar los sonidos de modo biunívoco. Y al mismo tiempo, en el prólogo de su Arte mexicano, fray Alonso insinúa que la expresión vocal es el reflejo de un alfabeto subyacente al que por cierto le faltan seis letras castellanas,

\footnotetext{
35 Molina, Arte mexicano, t. 2, f. 35rº.

${ }^{36}$ Ibid., t. 2, f. $34 v^{\circ}$.

37 Ibid., t. 2, f. $35 \mathrm{r}^{\mathrm{o}}$.

38 Ibid., t. 2, ff. $34 \mathrm{v}^{\mathrm{o}}, 35 \mathrm{r}^{\mathrm{o}}$.
} 
pero en el que hay por otra parte la "tsade", letra hebraica transcrita por TS o TZ39. Así se va completando una lista de todas las letras del náhuatl. Mas surge una dificultad:

Ytem, enesta legua [sic] ay cinco letras vocales, como enla latina y castellana: y son a, e, i, o, u, puesto que los naturales hagan poca diferencia entra la $\mathrm{o}$, y la v, porquanto vsan así dela una como dela otra indiferentemente $(i d$.$) .$

Entre las vocales fray Alonso distingue cinco letras y cinco sonidos. Pero como la O y la U se emplean "indiferentemente", aquí no podrá haber ni escritura ni habla ortográficas, sino sólo pronunciación y notación aproximadas. Un segundo problema parecido sobreviene. En el mexicano de aquel tiempo parece haber habido características fonéticas reservadas a un solo sexo, pues en ciertos casos contrastaba la pronunciación masculina de la $[\mathrm{u}]$ como vocálica con la pronunciación femenina de la [v] como consonántica. Fray Alonso explica:

Ytez $[s i c]$ los varones, no vsan de, v, consonante, aunque las mugeres Mexicanas, solamente, la vsen. Y assí dizen ellos veuetl, que es atabal, o tamborín, con quatro síllabas: y ellas dizen veuetl, con solas dos síllabas $(i d$.$) .$

El contenido de esta observación resultará bastante claro si no nos dejamos desconcertar por la tipografía vetusta en la que la $\mathrm{U}$ (al interior de la palabra) y la V (al inicio de la palabra) se emplean como alógrafos. En realidad, una sola forma escrita de la palabra se pronuncia de dos maneras distintas según la exprese un varón o una mujer. El discurso gramatical europeo no concibe que los sonidos de la voz puedan diferenciarse en función del sexo del sujeto hablante. Tampoco concede que la misma letra se pronuncie coincidentemente como vocal y como consonante ni que el número de sílabas de la misma palabra varíe de una persona a otra. Muy al contrario se exige la identidad de sonidos y letras y su repartición unívoca. Pero el Arte mexicano, evoca una situación en la que la bipartición radical de las voces masculina y femenina ya no encontrará su representación adecuada y unívoca en las letras del alfabeto. 
Por tercera vez, en el capítulo de los acentos, fray Alonso quebrantará las premisas de la representación en letras. Primero enumera varios ejemplos de la muy complicada acentuación nahua, y luego sigue diciendo:

y dado, que esta variedad y diferencia de accentos aquí dicha, sea prouechosa, empero muy mejor se puede saber y aprender con el vso, que con arte alguna, a causa dela diuersidad y variedad que ay en cada prouincia y en cada pueblo \&c. Mas porque es prouechosa esta materia: me pareció dar acerca della estos auisos que se siguen... El segundo auiso es, que particularmente preguntes alos naturales la costumbre y manera que tienen de pronunciar sus accentos, en qualesquier dictiones de su lengua, y hallada la escriuas para encomendarla bien ala memoria de manera que no se oluide ${ }^{40}$.

Aquí ni la escritura ni la gramática expresan inmediatamente la voz. Habrá que dejar el libro de fray Alonso y dirigirse a los aztecas para preguntarles su modo de pronunciar, y ni siquiera se podrá llegar a una codificación unívoca porque subsistirán las diferencias y variedades locales. Aunque el aprendiz de náhuatl vaya marcando luego las sílabas acentuadas, esta notación diacrítica resultará ser inevitablemente posterior al fenómeno vocal.

Así, la experiencia de que hay diferencia entre la letra y el sonido se encuentra paradójicamente rehabilitada por la gramática de fray Alonso. Esta experiencia había sido legada por el mundo amerindio cuando el discurso gramatical renacentista de los europeos había intentado precisamente exorcizarla, mas con la fijación alfabética del náhuatl se abrirá un nicho discursivo en el que se desgastarán subrepticiamente y desde dentro los supuestos del discurso gramatical importado. Puesto al contacto de la realidad vocal del Nuevo Mundo, fray Alonso se convierte en mestizo cultural, que asume el concepto de la representación identificadora y unívoca; es el primer gramático amerindio que rubrica simultáneamente la no identidad, la diferencia y la ambigüedad; nace así un discurso híbrido en la acepción de Mijaíl Bajtín y que corresponde mucho más al "bricolaje" de la mentalidad salvaje que a los axiomas científicos del Viejo Mundo, quizá un discurso hijo de la Malinche ${ }^{41}$.

40 Ibid., t. 2, ff. $27 \mathrm{v}^{\mathrm{o}}, 28 \mathrm{v}^{\mathrm{o}}$.

${ }^{41}$ Para la "hibridización" de voces y lenguas distintas, cf. Mijaíl BajTín, "Slovo v romane", Voprosy literatury i estetiki, Chudozestvennaja Literatura, Moskva, 1975; para el concepto de "bricolaje", Claude Lévi-Strauss, La pensée sauvage, Plon, Paris, 1962, pp. 30-36; para la interpretación de los discursos sobre América como híbridos, Irlemar Chiampi, O realismo Maravilhoso, Perspectiva, São Paulo, 1980. 
En Europa, los gramáticos habían identificado la letra con el sonido y, por ello, basaban su discurso en la exclusión de la voz sonora. Significativamente este postulado de la identidad ya no se mantiene intocable en el Nuevo Mundo, y con él periclita también el concepto de la representación. Es evidente que fray Alonso asimila las categorías alfabéticas, pero en vez de excluir lo no escrito, lo reflexiona como la exterioridad de su propio discurso. No rechaza por completo la representación, si bien la contempla dentro de sus propias limitaciones. En cierto modo, el Arte mexicano cristaliza en una "pensée du dehors", un pensamiento de lo de afuera, y de esta manera posibilita una relación del sujeto con la otredad que lo constituye.

Pero, ¿hasta dónde nos ha llevado, al fin y al cabo, nuestra reflexión sobre las estrechas vinculaciones recíprocas entre lenguaje, escritura y subjetividad?:

a) El lenguaje como la casa del ser, había dicho antaño un guardabosque filósofo de cuyo nombre no quiero acordarme.

b) El lenguaje como escritura del alfabeto sagrado, agregaría luego con mucho brío un cabalista parisiense.

Si así fuera, el discurso gramatical sobre la voz y la escritura se revelaría de manera inesperada como alegórico. Al tratar sonidos y letras remite, incesantemente, a la esencia o, mejor dicho, a la existencia del sujeto hablante. De tal manera el estudio de los discursos gramaticales permitiría elucidar, también, la espinosa cuestión colonial, pues desde los inicios de la Conquista la superposición de discursos arraigados, advenedizos e híbridos crea justamente aquellos intersticios de los que sale a la luz un arte de sí idiosincrásico. He aquí una posible genealogía del sujeto americano.

Bernardo Teuber 